\title{
Extracellular polymeric substance from Aphanizomenon flos-aquae induces apoptosis via the mitochondrial pathway in A431 human epidermoid carcinoma cells
}

\author{
XING XUE ${ }^{1,2}$, YING LV $^{3}$, QING LIU ${ }^{4}$, XIAOLAN ZHANG ${ }^{2}$, YOUHONG ZHAO ${ }^{4}$, LILI ZHANG ${ }^{2}$ and SHIYUAN XU ${ }^{1}$ \\ ${ }^{1}$ Department of Anesthesiology, Zhujiang Hospital, Southern Medical University, Guangzhou, Guangdong 510282; \\ ${ }^{2}$ Department of Anesthesiology, Gansu Provincial Maternity and Child-Care Hospital; \\ ${ }^{3}$ School of Environmental and Municipal Engineering, Lanzhou Jiaotong University, Lanzhou, Gansu 730070; \\ ${ }^{4}$ Department of Obstetrics and Gynecology, Gansu Provincial Maternity and Child-Care Hospital, \\ Lanzhou, Gansu 730070, P.R. China
}

Received August 29, 2014; Accepted July 2, 2015

DOI: $10.3892 / \mathrm{etm} .2015 .2644$

\begin{abstract}
Extracellular polymeric substance (EPS) is a substance secreted during algal growth, which has been found to have numerous health-promoting effects. In the present study, A431 human epidermoid carcinoma cells were selected as target cells and cultivated in vitro as an experimental model to investigate the anti-cancer effect of extracellular polymeric substances from Aphanizomenon flos-aquae (EPS-A) and the possible underlying mechanism. Apoptosis- and cell cycle-associated molecules as well as the mitochondrial membrane potential of the cells were quantified using flow cytometry (FCM). FCM showed that EPS-A induced cell cycle arrest, which led to a loss of mitochondrial function of the A431 cells and an increase in necrotic and late apoptotic cells. In order to evaluate the apoptosis and cell viability, acridine orange/ethidium bromide staining was used, morphological changes were observed using fluorescence microscopy and typical apoptotic characteristics were observed. Following treatment with a high dose of EPS-A, transmission electron microscopy showed nuclear fragmentation, chromosome condensation, cell shrinkage and expansion of the endoplasmic reticulum; apoptotic bodies were also observed. In conclusion, EPS-A caused cell cycle arrest, stimulated cell apoptosis via the mitochondrial pathway and exhibited important anti-cancer activity.
\end{abstract}

Correspondence to: Professor Shiyuan Xu, Department of Anesthesiology, Zhujiang Hospital, Southern Medical University, 253 Industrial Road, Guangzhou, Guangdong 510282, P.R. China E-mail: xushiyuan000@163.com

Key words: extracellular polymeric substances, apoptosis, anti-cancer, Aphanizomenon flos-aquae, human epidermoid carcinoma

\section{Introduction}

Experimental tests have been performed on various bioactive compounds from marine organisms, for the purpose of studying their biological effects and thereby identifying novel drugs. Natural products isolated from cyanobacteria have attracted great attention, since they comprise a valuable resource for providing promising drugs for the prevention and treatment of cancer $(1,2)$. Aphanizomenon flos-aquae is a filamentous and heterocytic cyanobacterium $(3,4)$, commonly found in nutrient-rich freshwaters as one of the dominant species in cyanobacterial bloom. During the growth process of an Aphanizomenon bloom outbreak, extracellular polymeric substances of A.flos-aquae (EPS-A), as well as paralytic shellfish poisons, are secreted into the surrounding environment (5). Extracellular polymeric substance (EPS), a high molecular weight biopolymer produced via excretion, secretion, sorption and cell lysis, is a substance secreted during algal growth (6). Recent studies have shown that algal EPS has an ecological importance and exhibits numerous biological activities (7-10). It has been found to have anti-thrombotic, -aging, -coagulant and -viral effects, be resistant to radiation, protect against endothelial cell damage, decrease hematic fat and blood sugar levels, regulate the immune response $(7,8)$ and induce cell apoptosis $(9,10)$.

Aberrant regulation of apoptosis is observed in a number of major human diseases, including cancer. Numerous therapeutic agents inhibit tumor cell growth by inducing apoptotic cell death. Mitochondria have also been found to play an important role in cell apoptosis (11). Apoptosis is a sequential process, during which unwanted cells are eliminated in a well-organized manner, and it is characterized by various biochemical and morphological changes, such as pyknosis, mitochondrial membrane permeability and plasma membrane blebbing. In apoptosis, an alteration in the permeability of the mitochondrial membrane causes the loss of mitochondrial membrane potential $(\Delta \Psi \mathrm{m})(12)$. Previous studies have reported that EPS can induce cell apoptosis $(9,10)$ and it is likely that, in the future, marine 
algae-derived materials/compounds will be used more widely in pre-clinical studies for drug discovery.

In the present study, A431 human epidermoid carcinoma cells were selected as the target cells, EPS-A from Lake Dianchi (Kunming, China) was used as the treatment agent and stabilized in vitro cultivation was conducted in order to observe the anticancer properties of EPS-A. The cell cycle and membrane potential of the mitochondria in the A431 cells were analyzed using flow cytometry (FCM), in order to explore the potential mechanism of apoptosis in A431 cells induced by EPS-A from Lake Dianchi. In the present study, the activities of EPS-A, including the inhibition of cell proliferation and induction of apoptosis in A431 cell lines, were reported, and the possibility that EPS-A could comprise the basis of an anticancer drug was investigated.

\section{Materials and methods}

Reagents. The A431 human epidermoid carcinoma cell line was purchased from the China Center for Type Culture Collection of Wuhan University (Wuhan, China). Fetal bovine serum (FBS) was purchased from Gibco-BRL (Grand Island NY, USA). Dulbecco's modified Eagle's medium (DMEM), Rhodamine 123 (Rh123) and nitroblue tetrazolium were purchased from Wuhan Boshide Biological Technology Co. (Wuhan, China) and propidium iodide (PI) was purchased from Sigma-Aldrich (St. Louis, MO, USA). All other chemicals were of the highest grade available from commercial sources.

Culture of A.flos-aquae. A strain of A.flos-aquae, isolated from Dianchi Lake in China, was obtained from the Freshwater Algae Culture Collection of the Institute of Hydrobiology, Chinese Academy of Sciences (Wuhan, China). According to methods of Zhang (13), with minor modifications. A.flos-aquae were cultured in $50 \mathrm{ml}$ sterilized BG11 medium for 30 days at $25 \pm 1^{\circ} \mathrm{C}$, with a $12 \mathrm{~h}$ light/dark cycle under a photon irradiance of $40 \mu \mathrm{E} / \mathrm{m}^{2} / \mathrm{s}$, which was provided by daylight fluorescent lamp. A. flos-aquae media were thoroughly shaken 2-3 times daily to prevent mat formation, then diluted into $1 \mathrm{~L}$ sterilized BG11 medium and cultured under identical conditions for a further 30 days. Large-scale culture was performed by diluting stock cultures $(1 \mathrm{~L})$ into $10 \mathrm{~L}$ sterile BG11 medium (cell concentration, $\sim 1 \times 10^{4}$ cells $/ \mathrm{ml}$ ). The culture media were harvested after 100 days.

Cell culture. The A431 cells were cultured in DMEM, supplemented with $10 \% \mathrm{FBS}$ and $100 \mathrm{U} / \mathrm{ml}$ penicillin-streptomycin at $5 \% \mathrm{CO}_{2}$ at a temperature of $37^{\circ} \mathrm{C}$. When they reached $85 \%$ confluence, cells were harvested using $0.25 \%$ trypsin and then subcultured in flasks measuring $75 \mathrm{~cm}^{2}$, as described in the following experiments. Fresh conditioned medium was added every 3 days and subcultures were digested by $0.25 \%$ trypsin every 7 or 8 days.

Morphological observation. The apoptosis and cell viability of cells treated with EPS-A were assessed by differential acridine orange/ethidium bromide (AO/EB) staining. A431 cells treated with phosphate-buffered saline (PBS) were also run under identical conditions and served as controls. Cells were collected after treatment with various concentrations of
EPS-A (1, 2, 3 and $4 \mathrm{mg} / \mathrm{ml})$ for $48 \mathrm{~h}$ before $20 \mu \mathrm{l}$ AO/EB dye $\operatorname{mix}(100 \mu \mathrm{l} / \mathrm{ml} \mathrm{AO}$ and $100 \mu \mathrm{l} / \mathrm{ml} \mathrm{EB}$, both prepared in PBS) was added. The suspension was concentrated via centrifugation at 2,800 x g for $5 \mathrm{~min}$ at room temperature, and the cell pellet was resuspended in $10 \mu \mathrm{l}$ cell suspension and plated on a clean slide; a coverslip was immediately placed on the slide. The analysis was conducted immediately using a fluorescence microscope (BX51TF; Olympus, Tokyo, Japan).

Cell cycle of the A431 cells. For the assessment of the effect of EPS-A on cell cycle progression, the A431 cells were incubated with $3 \mathrm{mg} / \mathrm{ml}$ EPS-A for 48 and $72 \mathrm{~h}$. The A431 cells treated with PBS were also run under identical conditions and served as controls. The cells were harvested using $0.25 \%$ trypsin, washed with $0.01 \mathrm{~mol} / 1 \mathrm{PBS}(\mathrm{pH} 7.4)$, counted and adjusted to $1 \times 10^{6}$ cells $/ \mathrm{ml}$. The cell suspension was then centrifuged at $560 \mathrm{x} \mathrm{g}$ for $5 \mathrm{~min}$ at room temperature. The cells were fixed in $70 \%$ ethanol, stained with $100 \mu \mathrm{g} / \mathrm{ml}$ PI for $30 \mathrm{~min}$ and subsequently analyzed using FCM (FACSCalibur ${ }^{\mathrm{TM}}$; BD Biosciences, Franklin Lakes, NJ, USA) at a 488-nm wavelength.

Rh123/PI double staining and FCM analysis. In order to further understand the $\Delta \Psi \mathrm{m}$ of the cells and the integrity of the cell membrane, as revealed by PI and Rh123 double staining, the A431 cells were incubated with $3 \mathrm{mg} / \mathrm{ml}$ EPS-A for $48 \mathrm{~h}$, and those treated with PBS were also run under identical conditions and served as controls. The cells were harvested using $0.25 \%$ trypsin, washed with $0.01 \mathrm{~mol} / 1 \mathrm{PBS}$ ( $\mathrm{pH} 7.4$ ), counted and adjusted to $1 \times 10^{6}$ cells $/ \mathrm{ml}$. The cell suspension was centrifuged at $560 \mathrm{x}$ g for $5 \mathrm{~min}$ at room temperature. Rh123 was then added to a final concentration of $1 \mathrm{mmol} / 1$ and the sample was incubated for $5 \mathrm{~min}$ at $37^{\circ} \mathrm{C}$ in the dark, washed with dye-free PBS, to eliminate non-specific binding of the dye to the mitochondria, and centrifuged again. PI was added to a final concentration of $100 \mu \mathrm{g} / \mathrm{ml}$ and the sample was incubated for $5 \mathrm{~min}$ at $37^{\circ} \mathrm{C}$ in the dark. Finally, the sample was resuspended in PBS and analyzed using FCM (FACSCalibur $^{\text {TM }}$ ) at a 488-nm wavelength.

Transmission electron microscopy (TEM). In order to study the EPS-A-induced apoptosis in A431 cells, the cells that had been treated with various concentrations of EPS-A (1, 2 and $3 \mathrm{mg} / \mathrm{ml}$ ) and PBS for $48 \mathrm{~h}$ were prefixed with $2.5 \% \mathrm{w} / \mathrm{v}$ glutaraldehyde for $2 \mathrm{~h}$, rinsed three times in $0.1 \mathrm{~mol} / \mathrm{l} \mathrm{PBS}(\mathrm{pH} 7.4$ ), and post-fixed for $2 \mathrm{~h}$ in $1 \% \mathrm{w} / \mathrm{v}$ osmium tetroxide at a temperature of $-4^{\circ} \mathrm{C}$. The fixed cells were dehydrated with a series of increasing concentrations of ethanol until they were completely dehydrated in absolute ethanol. The cells were detached using propylene oxide and then infiltrated with Spurr Low-Viscosity Embedding Medium (Wuhan Boshide Biological Technology Co., Wuhan, China). Sections were cut using an ultramicrotome with a diamond knife and stained with uranyl acetate and lead citrate. Observations were made using a transmission electron microscope (JEM-1230, Olympus Corporation, Tokyo, Japan).

\section{Results}

Morphological changes. In order to determine whether EPS-A induced apoptosis in the A431 cells, morphological changes 

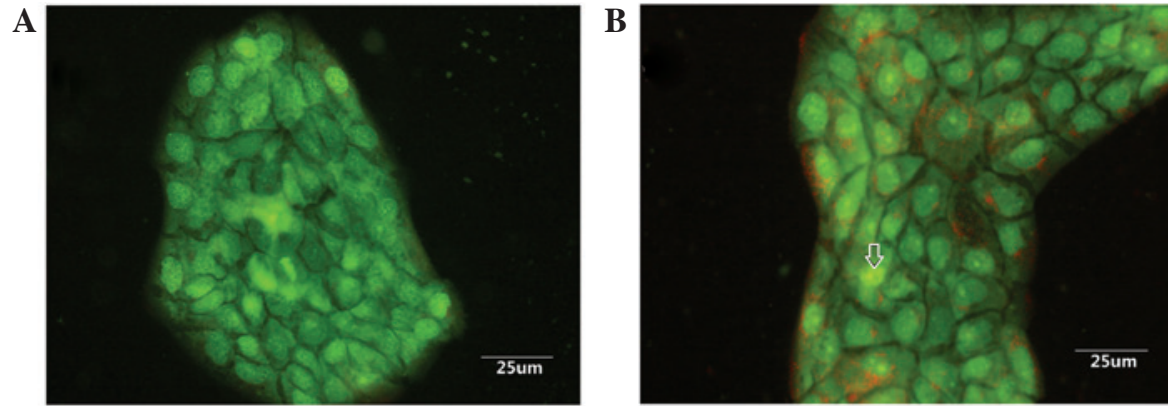

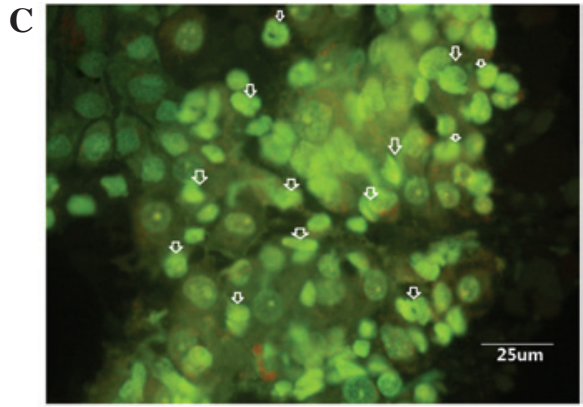

$\mathbf{E}$

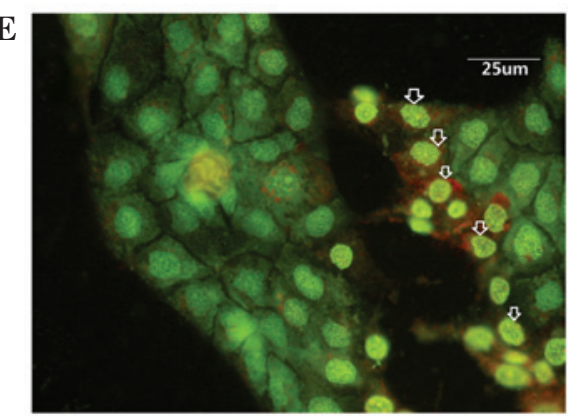

Figure 1. Morphological changes of A431 human epidermoid carcinoma cells stained with acridine orange/ethidium bromide following EPS-A treatment. (A) The control was treated with phosphate-buffered saline for $48 \mathrm{~h}$. (B-E) Cells treated with (B) 1 , (C) 2 , (D) 3 and (E) 4 mg/ml EPS-A for 48 h showed chromatin condensation and nuclear fragmentation. The arrows indicate apoptotic cells. EPS-A, extracellular polymeric substances of Aphanizomenon flos-aquae.

A

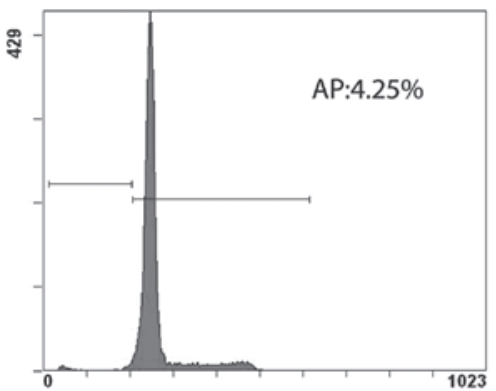

C

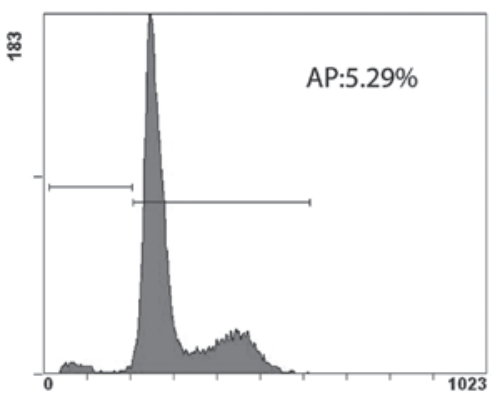

B

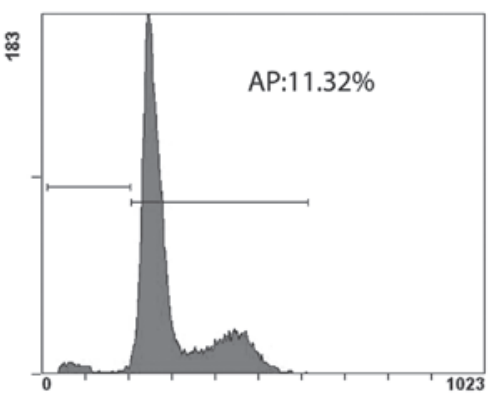

D

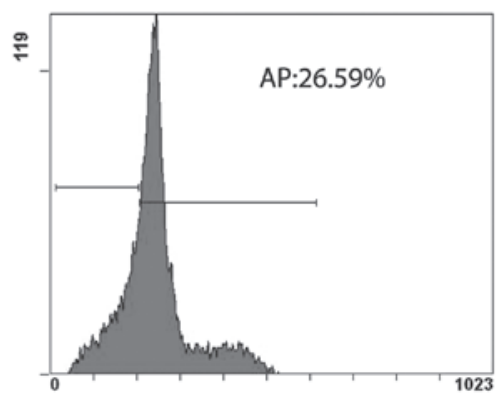

Figure 2. FCM analysis indicated that EPS-A induced cell cycle arrest and apoptosis in A431 cells stained with propidium iodide. (A-D) The control cells were treated with phosphate-buffered saline for (A) 48 and (C) $72 \mathrm{~h}$ and other A431 cells were treated with $3 \mathrm{mg} / \mathrm{ml} \mathrm{EPS}$-A for (B) 48 and (D) $72 \mathrm{~h}$, and their apoptotic rate was measured using flow cytometry. Each value represents the average of three independent experiments. EPS-A, extracellular polymeric substances of Aphanizomenon flos-aquae; AP, apoptotic rate.

were examined using a fluorescence microscope. It was shown that the cells exhibited an intact morphology of the nucleus and cytoplasm in the control group (Fig. 1A), while cells treated with EPS-A displayed typical apoptotic features (Fig. 1B-E).

EPS-A causes cell cycle arrest and induces apoptosis in A431 cells. The effect of EPS-A on the cell cycle progression of A431 cells was studied both 48 and $72 \mathrm{~h}$ after treatment. FCM analysis indicated that EPS-A caused cell cycle arrest and induced apoptosis in the A431 cells, which was not obvious at $48 \mathrm{~h}$ after treatment. The apoptotic rate of the control group was $4.25 \%$ (Fig. 2A), while that of the EPS-A group was $11.32 \%$ (Fig. 2B). At $72 \mathrm{~h}$ after treatment the apoptotic rate of the EPS-A group reached $26.59 \%$ (Fig. 2D), which was 5-fold higher than that of the control group (5.29\%; Fig. 2C).

Staining of A431 cells with PI and Rh123. Following FCM, the A431 cells that had been stained with Rh123/PI were easily 
A

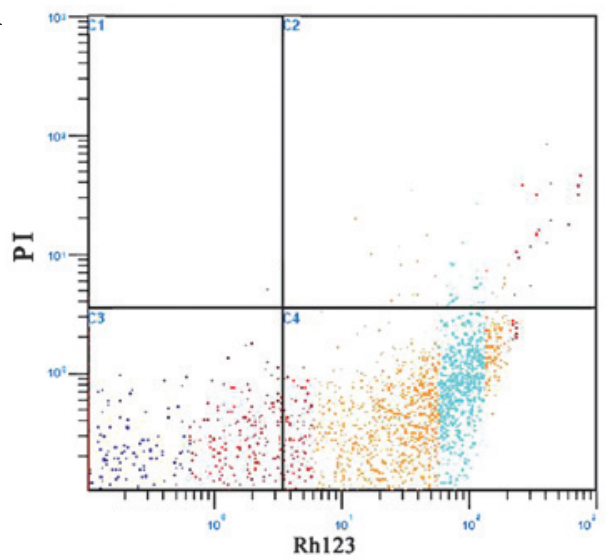

B

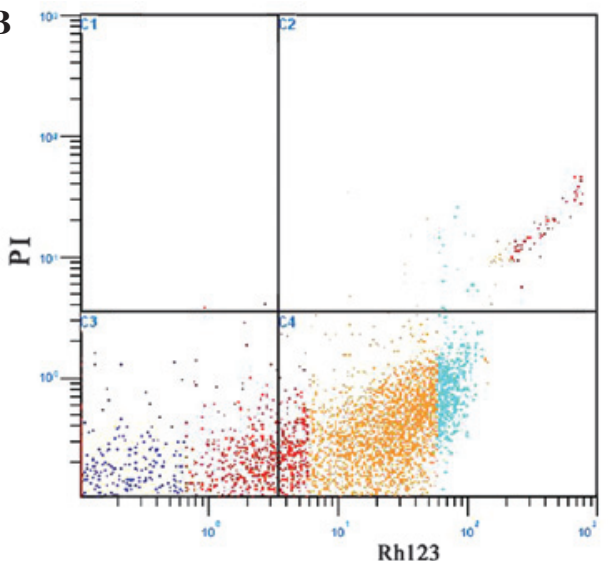

Figure 3. Staining of A431 cells with PI and Rh123 revealed that EPS-A induced apoptosis in A431 cells. (A) The control cells were treated with phosphate-buffered saline. (B) The A431 cells were treated with $3 \mathrm{mg} / \mathrm{ml}$ EPS-A for $48 \mathrm{~h}$, and their apoptotic rate was measured using flow cytometry. Cells were stained with Rh123 and PI. Each value represents the average of three independent experiments. Light blue represents normal cells, red represents necrotic cells, yellow and deep blue represent apoptotic cells. The lower right quadrant of each graph, Rh123+/PI', showed A431 cells with normal mitochondrial function; the lower left quadrant, Rh123/PI', showed A431 cells losing their mitochondrial function; the upper left quadrant, $\mathrm{Rh}^{-23} / \mathrm{PI}^{+}$, showed necrotic A431 cells and the upper right quadrant, $\mathrm{Rh} 123^{+} / \mathrm{PI}^{+}$, showed late apoptotic A431 cells. EPS-A, extracellular polymeric substances of Aphanizomenon flos-aquae; PI, propidium iodide; Rh123, Rhodamine 123.
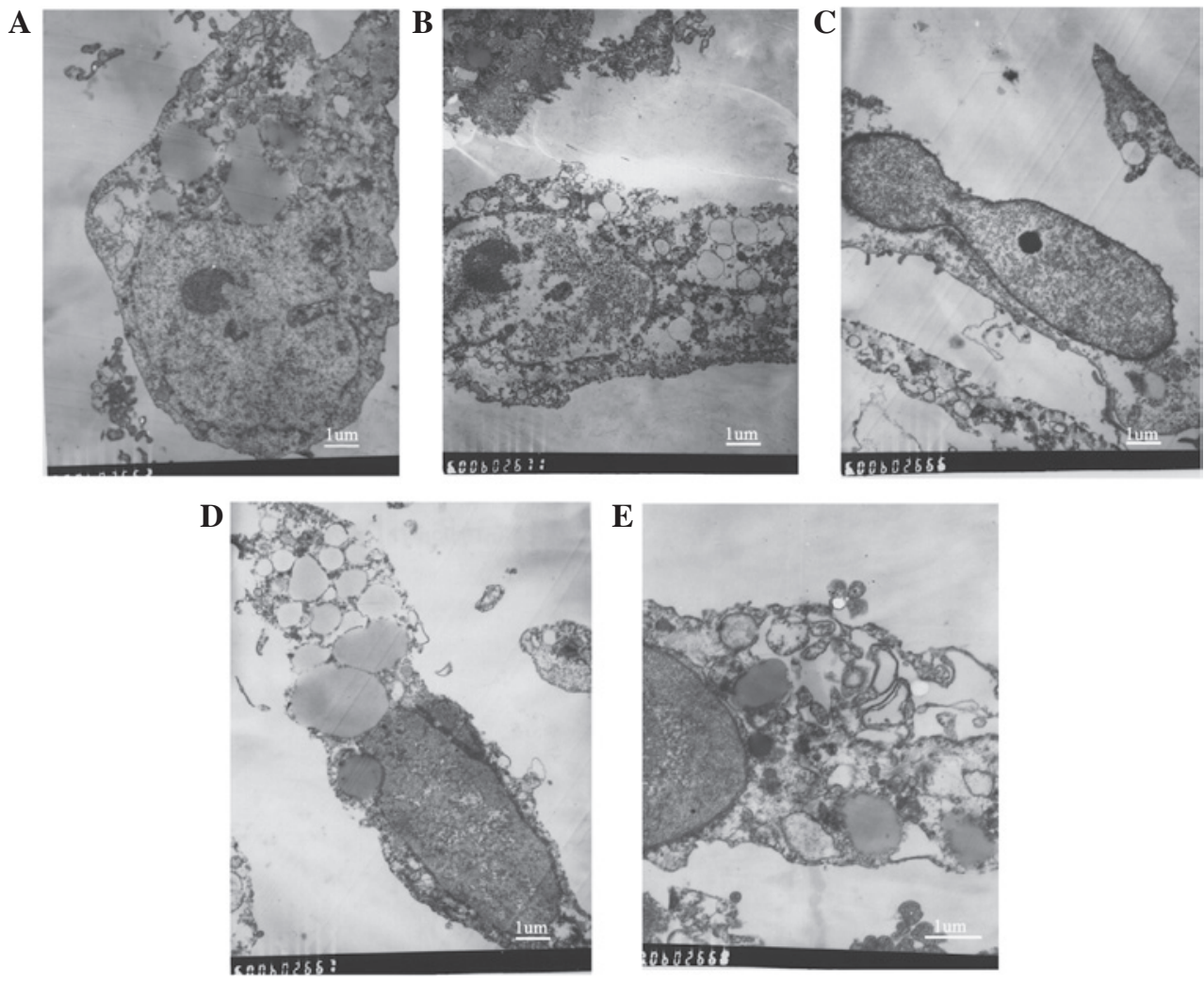

Figure 4. Transmission electron microscopy of ultrastructural changes in the A431 cells treated with varying concentrations of EPS-A. (A) The control cells were treated with phosphate-buffered saline for $48 \mathrm{~h}$. (B) Nuclear fragmentation, chromosome condensation, cell shrinkage and loss of membrane integrity were observed in the A431 cells treated with $1 \mathrm{mg} / \mathrm{ml}$ EPS-A for $48 \mathrm{~h}$; (C) severe chromosome condensation and cell shrinkage were observed in the A431 cells treated with $2 \mathrm{mg} / \mathrm{ml}$ EPS-A for $48 \mathrm{~h}$; (D) expansion of the endoplasmic reticulum was observed in the A431 cells treated with $2 \mathrm{mg} / \mathrm{ml}$ EPS-A for $48 \mathrm{~h}$, and (E) apoptotic bodies were observed in the A431 cells treated with $3 \mathrm{mg} / \mathrm{ml}$ EPS-A for $48 \mathrm{~h}$ (scale bar=1 micron). EPS-A, extracellular polymeric substances of Aphanizomenon flos-aquae.

divided into four groups (Fig. 3): The lower right quadrant of

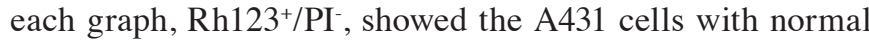
mitochondrial function; the lower left quadrant contained Rh123\% /PI A431 cells that had lost their mitochondrial function; the upper left quadrant, $\mathrm{Rh} 123 \% / \mathrm{PI}^{+}$, showed necrotic
A431 cells and the upper right quadrant, $\mathrm{Rh} 123^{+} / \mathrm{PI}^{+}$, showed late apoptotic A431 cells. As shown in Fig. 3A, the A431 cells in the $\mathrm{Rh} 123^{+} / \mathrm{PI}^{-}$group were centered in the lower right quadrant, which meant that the A431 cells in the control group exhibited a good mitochondrial function. The A431 cells of 
the EPS-A group; however, were predominantly concentrated in the lower left and lower right quadrants, which indicated that the A431 cells in the EPA-S group had lost mitochondrial function and the number of apoptotic A431 cells had increased (Fig. 3B).

Effects of EPS-A on the ultrastructure of the A431 cells. The ultrastructural changes of the A431 cells were observed using TEM. The cell ultrastructure of the control group was observed to be normal (Fig. 4A). Following treatment with a low dose of EPS-A, nuclear fragmentation, chromosome condensation and cell shrinkage (Fig. 4B and C) were observed in the A431 cells. Their rough-surfaced endoplasmic reticulum exhibited enlarged cisternae (Fig. 4D). Following treatment with a higher dose of EPS-A, apoptotic bodies were observed (Fig. 4E).

\section{Discussion}

Numerous bioactive extracellular polymeric substances with noteworthy functional properties have been discovered in marine organisms, and studies that focus on marine natural products, particularly marine algae EPS, are increasingly attracting worldwide attention $(8,13)$. Natural products that have been isolated from cyanobacteria, as well as their derivatives, have been proven to be a valuable chemical resource for finding promising drugs that could assist the prevention and treatment of cancer (14). The aim of the present study was to evaluate the effect that EPS-A has on A431 cells and to explore its anticancer activity.

Apoptosis is an important aspect of chemotherapy-induced tumor cell death as well as the major mechanism by which numerous anticancer drugs and natural products induce cell death (15). Apoptosis is also a type of programmed cell death, which, through a series of biochemical events, leads to cellular morphological changes and cell death. In order to explore the mechanism responsible for the anticancer effects of EPS-A, the changes in cell morphology were assessed. Following treatment with different concentrations of EPS-A, morphological changes, including cell shrinkage, nuclear fragmentation and chromatin condensation, were observed in the A431 cells. AO/EB staining of EPS-A-treated A431 cells showed that EPS-A resulted in nuclear condensation and fragmentation, a morphological hallmark of apoptosis (16).

In the present study, FCM analysis revealed that EPS-A treatment resulted in an increase in the proportion of apoptotic cells. When treated for $48 \mathrm{~h}$, the proportion of apoptotic cells in the EPS-A group was low, mainly due to the fact that there had been no loss of DNA by fragmentation, although DNA damage occurred at an early phase of apoptosis. The secondary reason may be that for apoptotic cells in the $S$ or $\mathrm{G}_{2} / \mathrm{M}$ phase, even if the DNA content decreased, the actual DNA content was not lower than that of diploid cells, and the proportion of cells in the $\mathrm{S}$ and $\mathrm{G}_{2} / \mathrm{M}$ phases in the EPS-A group was higher than that in the control group. This may be due to the fact that EPS-A caused cell cycle arrest of the A431 cells in the $G_{2} / M$ phase, affected spindle formation during cell division and inhibited cell division $(17,18)$. At $72 \mathrm{~h}$ the apoptosis peak $\left(\mathrm{G}_{2} / \mathrm{M}\right)$ was not obvious. The results suggested that EPS-A initially affected the $S$ and $G_{2} / M$ phases of the A431 cells at the early treatment stage, induced cell cycle arrest in the $S$ and $G_{2} / M$ phases and then cell apoptosis, and the proportion of apoptotic cells increased in a time-dependent manner. Therefore, EPS-A induced apoptosis of the A431 cells by affecting the whole cell cycle, but the exact mechanism remains unclear.

In the early phase of apoptosis, when changes in mitochondrial morphology are undetectable, the dissipation of the membrane potential has already occurred. The dissipation of the membrane potential is considered to be part of a cascade reaction that occurs early in the process of apoptosis, prior to nuclease enzyme activation and the exposure of phosphatidylserine at the cell surface. Once the $\Delta \Psi \mathrm{m}$ is dissipated, apoptosis is irreversible $(19,20)$.

The fluorescent dyes Rh123 and PI can be used to evaluate the function of the mitochondria and nucleus, respectively (21). In order to further understand the $\Delta \Psi \mathrm{m}$ of a cell and the integrity of the cell membrane, PI and Rh123 double staining was carried out. PI is a fluorescent dye that is not membrane permeable and binds to DNA, whereas Rh123 is a lipophilic dye that is absorbed by the mitochondria. When the integrity of the cell membrane is intact, PI is not able to enter the cell to stain the DNA; therefore, a lack of PI staining indicates cell membrane integrity. The presence of Rh123 staining suggests that the $\Delta \Psi \mathrm{m}$ is normal. The cellular uptake of Rh123 is positively correlated with the $\Delta \Psi \mathrm{m}$ (22). FCM analysis showed that the cells comprised two main subpopulations: PI-Rh123+ cells that retained their cell membrane integrity and had a 'steady state' $\Delta \Psi \mathrm{m}$, and PI'Rh $123^{+}$cells that retained their cell membrane integrity but had a decreased $\Delta \Psi \mathrm{m}$. In the cells treated with EPS-A for 48 h, the number of Rh123 PI $^{-}$cells (those with neither PI nor Rh123 staining) increased. This indicated that some of the cells had an intact cell membrane but had lost $\Delta \Psi \mathrm{m}$. In conclusion, EPS-A may induce the apoptosis of A431 cells by regulating the mitochondrial membrane permeability.

To date, cell ultrastructure observation using TEM comprises the most common and reliable method of detecting apoptosis, and is considered as the gold standard. TEM showed visible cell nuclei, uniform chromatin distribution, abundant organelles and cell membrane and nuclear membrane integrity in the control group. Following treatment with a low dose of EPS-A for $48 \mathrm{~h}$, nuclear fragmentation, chromosome condensation, cell shrinkage and expansion of the endoplasmic reticulum were observed in the A431 cells. Following treatment with a high dose of EPS-A, the shape of the A431 cells was markedly altered, and apoptotic bodies were observed. The results showed that EPS-A influenced the A431 cell structure in a direct manner, disrupted cell metabolism, damaged DNA and ultimately induced apoptosis in the A431 cells.

In conclusion, the results showed that EPS-A has anti-cancer properties and can induce apoptosis in A431 cells via the mitochondrial pathway. The cause of apoptosis in A431 cells may be cell cycle arrest and collapse of the $\Delta \Psi \mathrm{m}$; therefore, EPS-A plays an important anti-cancer role, the exact mechanism of which, however, requires further research.

\section{Acknowledgements}

The present study was supported by the Natural Science Foundation of Gansu Province of China (grant no. 145RJZA171). 
The authors would like to thank Professor Chunxiang $\mathrm{Hu}$, Delu Zhang and Yongding Liu for their assistance in the running of the experiments.

\section{References}

1. Tan W, Lu J, Huang M, et al: Anti-cancer natural products isolated from chinese medicinal herbs. Chin Med 6: 27, 2011.

2. Monks NR, Li B, Gunjan S, et al: Natural products genomics: A novel approach for the discovery of anti-cancer therapeutics. J Pharmacol Toxicol Methods 64: 217-225, 2011

3. DE Nobel WT, Matthijs HCP, Elert, von Elert E and Mur LR: Comparison of the light-limited growth of the nitrogen-fixing cyanobacteria Anabaena and Aphanizomenon. New Phytologist 138: 579-587, 1998.

4. Reynolds CS, Huszar V, Kruk C, et al: Towards a functional classification of the freshwater phytoplankton. J Plankton Res 24: 417-428, 2002

5. Liu Y, Chen W, Li D, et al: First report of aphantoxins in China - waterblooms of toxigenic Aphanizomenon flos-aquae in lake Dianchi. Ecotoxicol Environ Saf 65: 84-92, 2006.

6. Klock J, Wieland A, Seifert R and Michaelis W: Extracellular polymeric substances (EPS) from cyanobacterial mats: Characterisation and isolation method optimisation. Marine Biol 152: 1077-1085, 2007.

7. Mooberry SL, Leal RM, Tinley TL, et al: The molecular pharmacology of symplostatin 1: A new antimitotic dolastatin 10 analog. Int J Cancer 104: 512-521, 2003.

8. Singh RK, Tiwari SP, Rai AK and Mohapatra TM: Cyanobacteria: An emerging source for drug discovery. J Antibiot (Tokyo) 64 401-412, 2011

9. Park HK, Kim IH, Kim J and Nam TJ: Induction of apoptosis by laminarin, regulating the insulin-like growth factor-IR signaling pathways in HT-29 human colon cells. Int J Mol Med 30: 734-738, 2012

10. Xue M, Ge Y, Zhang J, et al: Anticancer properties and mechanisms of fucoidan on mouse breast cancer in vitro and in vivo. PLoS One 7: e43483, 2012.

11. Ou Y, Xu S, Zhu D, et al: Molecular mechanisms of exopolysaccharide from Aphanothece halaphytica (EPSAH) induced apoptosis in HeLa cells. PLoS One 9: e87223, 2014.

12. Hou R, Zhou QL, Wang BX, et al: Diosgenin induces apoptosis in HeLa cells via activation of caspase pathway. Acta Pharmacol Sin 25: 1077-1082, 2004.
13. Zhang D, Hu C, Wang G, Li D, Li G and Liu Y: Zebrafish neurotoxicity from aphantoxins - cyanobacterial paralytic shellfish poisons (PSPs) from Aphanizomenon flos-aquae DC-1. Environ Toxicol 28: 239-254, 2013

14. Yap TA and Workman P: Exploiting the cancer genome: Strategies for the discovery and clinical development of targeted molecular therapeutics. Annu Rev Pharmacol Toxicol 52: 549-573, 2012

15. Yang L, Wang $\mathrm{P}$, Wang $\mathrm{H}$, et al: Fucoidan derived from Undaria pinnatifida induces apoptosis in human hepatocellular carcinoma SMMC-7721 cells via the ROS-mediated mitochondrial pathway. Mar Drugs 11: 1961-1976, 2013.

16. Alarifi S, Ali D, Alakhtani S, et al: Reactive oxygen species-mediated DNA damage and apoptosis in human skin epidermal cells after exposure to nickel nanoparticles. Biol Trace Elem Res 157: 84-93, 2014.

17. Zhang X, Chen W, Guillermo R, et al: Alpha-santalol, a chemopreventive agent against skin cancer, causes G2/M cell cycle arrest in both p53-mutated human epidermoid carcinoma A431 cells and p53 wild-type human melanoma UACC-62 cells. BMC Res Notes 3: 220, 2010

18. Ma S, Shan LQ, Xiao YH, et al: The cytotoxicity of methacryloxylethyl cetyl ammonium chloride, a cationic antibacterial monomer, is related to oxidative stress and the intrinsic mitochondrial apoptotic pathway. Braz J Med Biol Res 44: 1125-1133, 2011.

19. Lemasters JJ, Nieminen AL, Qian T, Trost LC, Elmore SP, Nishimura Y, Crowe RA, Cascio WE, Bradham CA, Brenner DA and Herman B: The mitochondrial permeability transition in cell death: A common mechanism in necrosis, apoptosis and autophagy. Biochim Biophys Acta 1366: 177-196, 1998.

20. Xu F, Zhang SH, Shao RG and Zhen YS: Anticancer activity of sodium caffeate and its mechanism. Acta Pharmacol Sin 26: $1248-1252,2005$

21. Galfano A, Novara G, Iafrate M, et al: Improvement of seminal parameters and pregnancy rates after antegrade sclerotherapy of internal spermatic veins. Fertil Steril 91: 1085-1089, 2009.

22. Zou T, Liu X, Ding S, Xing J: Evaluation of sperm mitochondrial function using rh123/PI dual fluorescent staining in asthenospermia and oligoasthenozoospermia. J Biomed Res 24: 404-410, 2010. 